\title{
Transporte de oócitos bovinos em meio de maturação sem controle de atmosfera gasosa
}

\author{
Transport of bovine oocytes in maturation medium without a controlled gaseous atmosphere
}

\author{
Fábio Gallas Leivas ${ }^{1}$ Daniela dos Santos Brum ${ }^{2}$ Alceu Mezzalira ${ }^{3}$ Luis Fernando Cáceres Pilla \\ Mari Lourdes Bernardi ${ }^{5}$ Mara Iolanda Batistella Rubin ${ }^{6}$ Carlos Antonio Mondino Silva ${ }^{6}$
}

\section{RESUMO}

Oócitos ( $n=1177)$ bovinos obtidos da aspiração de folículos com diâmetro entre 2 e $8 \mathrm{~mm}$, de ovários de matadouro foram divididos aleatoriamente em quatro tratamentos com 11 repetições. Os oócitos foram maturados por $24 \mathrm{~h}$ em TCM-199 Sais de Earle, acrescido de 25mM de bicarbonato de sódio, $25 \mathrm{mM}$ de HEPES, rFHS- $h$, Soro de Vaca em Estro (SVE) e piruvato, em estufa a $39^{\circ} \mathrm{C}$, com $5 \%$ de $\mathrm{CO}_{2}$ em ar e umidade saturada (Grupo Controle, $n=296$ ) ou, submetidos ao transporte simulado por $6(T 6, n=286), 12$ $(T 12, n=294)$ ou $18 h(T 18, n=301)$ em meio de maturação TCM+HEPES, em banho-maria a $39^{\circ} \mathrm{C}$, com os mesmos componentes utilizados para o Grupo Controle, porém com apenas $1 \mathrm{mM}$ de bicarbonato. Decorrido cada período de transporte, os mesmos foram transferidos para placas com meio de maturação, completando o período de $24 \mathrm{~h}$ em estufa, nas mesmas condições do Grupo Controle. O período de fecundação foi de $18 \mathrm{~h}$ em condições semelhantes de temperatura e atmosfera gasosa, em FERT-TALP acrescido de heparina, sendo a dose inseminante de $1 \times 10^{6}$ espermatozóides $/ m L$, selecionados por migração ascendente. Os prováveis zigotos foram cultivados em meio $\mathrm{SOF}+5 \%$ SVE por 8 dias, em estufa a $39^{\circ} \mathrm{C}$, em bolsas gaseificadas com $5 \% \mathrm{CO}_{2}, 5 \% \mathrm{O}_{2}$ e $90 \% \mathrm{~N}$. $\mathrm{Na}$ avaliação da clivagem, não houve diferença entre os tratamentos. As taxas de desenvolvimento embrionário no dia 7 foram semelhantes para os grupos Controle (20,9\%), T6 (19,2\%) e T12 (21,4\%), com uma redução $(P<0,05)$ observada no grupo $T 18$ (12,3\%), em relação aos grupos Controle e T12. No dia 9, o T18 apresentou uma menor $(P<0,05)$ produção de blastocistos expandidos mais eclodidos, em relação aos demais grupos, embora não tenha sido observada diferença $(P>0,05)$ na taxa de eclosão. $O$ número médio de células dos blastocistos eclodidos não diferiu $(P>0,05)$ entre os grupos Controle (136), T6 (125,5) e T12 (126,8). Esses resultados indicam a possibilidade do transporte de oócitos bovinos em meio de maturação TCM+HEPES, sem controle da atmosfera gasosa, a $39^{\circ} \mathrm{C}$, pelo período de até $12 \mathrm{~h}$. Esta técnica oferece uma alternativa prática e eficiente para o transporte dos oócitos bovinos destinados à produção in vitro de embriões bovinos (PIV).

Palavras-chave: oócitos bovinos, Hepes, OPU, PIV, transporte.

\section{ABSTRACT}

Oocytes $(n=1177)$ aspirated from 2 to $8 \mathrm{~mm}$ follicles obtained from bovine slaughterhouse ovaries (11 replications) were randomly distributed in four treatments. Oocytes were matured for $24 \mathrm{~h}$ with modified TCM-199 Earle salts, plus $25 \mathrm{mM}$ bicarbonate, $25 \mathrm{mM}$ HEPES, rFSH-h, Estrus Cow Serum (ECS), and piruvate at $39^{\circ} \mathrm{C}$, in incubator with $5 \% \mathrm{CO}_{2}$ and saturated humidity (Control Group, $n=296$ ) or exposed to a simulated transport for 6 (T6, $n=286), 12$ (T12, $n=294)$ or $18 \mathrm{~h}(T 18, n=301)$ in maturation medium containing TCM + HEPES, in a $39^{\circ} \mathrm{C}$ water bath, with the same components used in the Control Group, but with $1 \mathrm{mM}$ bicarbonate. At the conclusion of each transport period, oocytes were transferred to dishes with maturation medium to reach $24 \mathrm{~h}$ in incubator, under the same conditions described for the Control group. Fertilization was accomplished during $18 \mathrm{~h}$, with the same temperature and gaseous atmosphere, in

\footnotetext{
${ }^{1}$ Médico Veterinário, aluno do Programa de Pós-graduação em Medicina Veterinária (PPGMV), Universidade Federal de Santa Maria (UFSM), Rua José Bonifácio, 2680/504, 97015-450, Santa Maria, RS. Autor para correspondência: e-mail:fabioleivas@yahoo.com.br ${ }^{2}$ Médico Veterinário, Doutoranda do PPGMV, UFSM.

${ }^{3}$ Médico Veterinário, Doutor, Professor Titular, Departamento de Clínica e Patologia do Centro de Ciências Agroveterinárias, Lages, SC.

${ }^{4}$ Aluno de graduação em Medicina veterinária, Bolsista PIBIC/CNPq, UFSM.

${ }^{5}$ Médico Veterinário, Doutor, Departamento de Zootecnia, Faculdade de Agronomia, UFRGS, Porto Alegre, RS

${ }^{6}$ Médicos Veterinários, Doutores, Professores titulares, EMBRYOLAB, Departamento de Clínica de Grandes Animais, UFSM, 97105-900, Santa Maria, RS.
} 
FERT-TALP plus heparin. The insemination dose was $1 \times 10^{6}$ spermatozoa/mL, sorted by swim-up. Presumptive zygotes were cultured in SOF medium $+5 \%$ ECS for 8 days, in incubator at $39^{\circ} \mathrm{C}$ using gasified bags with $5 \% \mathrm{CO}_{2}, 5 \% \mathrm{O}_{2}$ and $90 \% \mathrm{~N}_{2}$. Cleavage rates did not differ between treatments. Embryonic development rates at D7 were similar for Control (20.9\%), T6 $(19.2 \%)$ and $T 12(21.4 \%)$ groups, with a reduction $(P<0.05)$ for group $T 18(12.3 \%)$ when compared to Control and T12 groups. At D9, there was a lower production of expanded plus hatched blastocysts in $T 18$ ( $P<0.05)$, without difference $(P>0.05)$ in hatched blastocyst rate. The average number of cells of hatched blastocysts was similar $(P>0.05)$ in Control (136), T6 (125.5) and T12 (126.8) groups. These results indicate the possibility of transporting bovine oocytes in maturation medium containing TCM + HEPES, without controlled gaseous atmosphere environment, at $39^{\circ} \mathrm{C}$, for up to 12 hours. This technique offers a practical and efficient alternative for the transport of bovine oocytes for in vitro production of bovine embryos (IVP).

Key words: bovine oocytes, Hepes, OPU, IVP, transportation.

\section{INTRODUÇÃO}

Para a produção in vitro de embriões bovinos (PIV), os oócitos podem ser obtidos de ovários de matadouro ou de animais vivos, neste último caso pela ovariectomia, laparoscopia ou ainda através da aspiração folicular transvaginal (OPU). Apesar dos avanços nas técnicas de recuperação de oócitos, há poucos estudos sobre o transporte até o laboratório de PIV, de oócitos obtidos de OPU (SCHERTHANER et al., 1998; WOLF et al., 1998; WARD et al., 2000; FRY et al., 2000).

Blastocistos bovinos produzidos in vitro podem ser mantidos em meios não gaseificados (SCHNEIDER et al., 1998; MEZZALIRA et al., 1998) ou, ainda, em meios gaseificados por até 24h (BRUM et al., 2000/2001), sem prejuízos às taxas de evolução embrionária e prenhez. Entretanto, os oócitos necessitam de condições mais controladas, sendo o meio utilizado, a duração do transporte e a temperatura entre a coleta e a chegada dos oócitos no laboratório, aspectos que influenciam o desenvolvimento embrionário (WARD et al., 2000). SCHWARTZ et al. (1998) concluíram que a temperatura de armazenamento influencia mais no desenvolvimento embrionário que o meio utilizado.

O Fluído Folicular bovino (FFb), obtido de folículos entre 2 e $8 \mathrm{~mm}$ de diâmetro, pode ser uma alternativa para a manutenção dos oócitos, por curtos períodos de tempo, até a chegada no laboratório (VIZCARRA et al., 2000; LEHMKUHL et al., 2000). A manutenção em FFb pelo período de $24 \mathrm{~h}$, apesar de reduzir a PIV, não impediu o desenvolvimento embrionário (MONTAGNER et al., 1997). Os meios
TALP-HEPES e TCM+BSA também têm sido utilizados com sucesso para o armazenamento de oócitos bovinos destinados à PIV, por períodos que variam de 5 a $10 \mathrm{~h}$, conforme a temperatura utilizada (SCHERTHANER et al., 1998; WOLF et al., 1998; SCHWARTZ et al., 1998).

Os meios de cultivo utilizados na Maturação in vitro (MIV) são essenciais para a maturação dos oócitos bovinos, permitindo que atinjam a metáfase II, possibilitando a fecundação, e influenciando, também, nas taxas de desenvolvimento embrionário in vitro (ROSE \& BAVISTER, 1992). Podem ser divididos em simples ou complexos. Os simples são constituídos de uma solução salina acrescida de uma fonte energética e um tamponante de $\mathrm{pH}$, sendo o sistema HEPES-Bicarbonato/ $\mathrm{CO}_{2}$ o mais utilizado, além de serem geralmente suplementados com antibióticos, soro ou albumina. Com relação à atmosfera gasosa, o $\mathrm{CO}_{2}$ é utilizado para controlar o $\mathrm{pH}$ dos meios tamponados com bicarbonato (BOONE \& SHAPIRO, 1990). O HEPES vem sendo muito utilizado como tampão para evitar grandes variações de $\mathrm{pH}$ nos meios de maturação e cultivo embrionário (TWAGIRAMUNGU et al. 1998; FRY et al., 2000; MONTAGNER et al., 2000), além de ser o mais utilizado para remessa de oócitos coletados e destinados à PIV.

A produção de embriões em tubos de poliestireno previamente gaseificados e mantidos em banho-maria para manutenção da temperatura foi comprovada por OLIVIER et al. (1998). Comparando diferentes meios de transporte de oócitos, previamente equilibrados em estufa, TWAGIRAMUNGU et al. (1998) observaram que para períodos de até 6h não havia diferença nas taxas de PIV, entre TCM e TCM+HEPES previamente equilibrados em estufa, embora para períodos superiores, a produção de blastocistos tenha sido afetada em relação ao grupo controle. Outros autores também não observaram diferenças na capacidade de desenvolvimento dos oócitos mantidos em meios tamponados com HEPES ou bicarbonato (WARD et al., 2000).

No Brasil, em função da grande extensão territorial, as condições de transporte dos oócitos até o laboratório de PIV são consideradas como fator limitante na produção comercial pois, em muitos casos, o transporte até o laboratório pode demorar várias horas. Os bons resultados obtidos com o transportesimulado, em meio de maturação, sem controle de atmosfera gasosa, por 6h (LEIVAS et al., 2001), evidenciaram a necessidade de avaliar períodos mais longos de transporte nessas condições. A adequação desta metodologia constituirá importante ferramenta para o incremento da produção in vitro de embriões, 
evitando o inconveniente da gaseificação prévia dos meios de MIV e facilitando o transporte de oócitos coletados em locais mais distantes. Este trabalho teve como objetivo avaliar os índices de produção de blastocistos e a sua viabilidade após o transporte simulado de oócitos bovinos por períodos de 6,12 e $18 \mathrm{~h}$ em meio de maturação TCM+HEPES a $39^{\circ} \mathrm{C}$, sem controle da atmosfera gasosa.

\section{MATERIAL E MÉTODOS}

\section{Coleta dos ovários e seleção dos oócitos}

Para a PIV, os oócitos foram obtidos a partir de ovários provenientes de frigorífico, transportados até o laboratório a $30^{\circ} \mathrm{C}$, em solução de $\mathrm{NaCl}$ a $0,9 \%$, acrescida de 50UI/mL de penicilina G-Potássica e $100 \mathrm{mg} / \mathrm{mL}$ de estreptomicina. Foram aspirados os folículos com diâmetro entre 2-8 mm, com auxílio de uma bomba de vácuo ${ }^{\mathrm{b}}$. Os oócitos recuperados foram mantidos em líquido folicular para busca e seleção sob estereomicroscópio, sendo selecionados para a maturação os oócitos de qualidade 1 e 2, segundo os critérios descritos por De LOOS et al. (1989).

\section{Maturação in vitro dos oócitos}

Após a seleção, os oócitos foram dstribuídos aleatoriamente em 4 tratamentos. Os oócitos do Grupo Controle foram submetidos à MIV em placas Nunc ${ }^{c}$, em gotas de $400 \mu \mathrm{L}$ de meio de maturação TCM-199d Sais de Earle, adicionado de $2,2 \mathrm{mg} / \mathrm{mL}$ de bicarbonato de sódio $(25 \mathrm{mM}), 5,95 \mathrm{mg} / \mathrm{mL}$ de HEPES (25mM), 0,025 mg/mL de piruvato de sódio, $0,01 \mathrm{UI}$ de $\mathrm{rFSHh} / \mathrm{mL}$ e $10 \%$ de SVE , em estufa com $5 \%$ de $\mathrm{CO}_{2} \mathrm{em}$ ar, $39^{\circ} \mathrm{C}$ e umidade saturada, por $24 \mathrm{~h}$. Os oócitos dos tratamentos submetidos ao transporte simulado (T6, T12, T18), foram mantidos em tubos de poliestireno ${ }^{\mathrm{c}}$ contendo $400 \mu \mathrm{L}$ de meio de maturação TCM+HEPES $(\mathrm{pH} 7,4)$ com todos os componentes utilizados para o Grupo Controle, porém com apenas $1 \mathrm{mM}$ de bicarbonato de sódio, cobertos por óleo mineral por 6,12 ou $18 \mathrm{~h}$, em banho-maria a $39^{\circ} \mathrm{C}$. Após este período, os oócitos de cada tratamento foram transferidos para placas com meio de maturação, nas mesmas condições do grupo Controle, e permaneceram o tempo necessário para completar $24 \mathrm{~h}$ de maturação.

\section{Fecundação in vitro dos oócitos}

Decorrido o período de MIV, os oócitos foram transferidos para gotas de $400 \mu \mathrm{L}$ de meio TALPFERT, com $6 \mathrm{mg} / \mathrm{mL}$ de BSA e $0,22 \mathrm{mg} / \mathrm{mL}$ de piruvato de sódio, acrescido de $30 \mu \mathrm{g} / \mathrm{mL}$ de heparina, previamente equilibrado em estufa por duas horas. Para a fecundação foi utilizado sêmen congelado de um pool de dois touros Bos taurus, selecionados em TALPSPERM, por migração ascendente ("swim-up"). A dose inseminante utilizada foi de $1 \times 10^{6}$ espermatozóides $/ \mathrm{mL}$. A incubação dos oócitos/espermatozóides foi conduzida em estufa de cultivo a $39^{\circ} \mathrm{C}$, com $5 \%$ de $\mathrm{CO}_{2}$ em ar, com umidade saturada, por um período de $18 \mathrm{~h}$.

\section{Cultivo in vitro dos embriões}

Após o período de fecundação, os oócitos/ zigotos foram submetidos à agitação mecânica para a retirada das células do Cumulus oophorus e, em seguida, transferidos para gotas de $400 \mu \mathrm{L}$ de meio SOF, acrescido de $20 \mu \mathrm{L} / \mathrm{mL}$ de aminoácidos essenciais e $10 \mu \mathrm{L} / \mathrm{mL}$ de aminoácidos não-essenciais + 5\% de SVE em placas Nunc sob óleo mineral, durante 8 dias. $\mathrm{O}$ sistema de cultivo empregado foi o Bag System, que consiste na manutenção das placas de cultivo embrionário, no interior de bolsas $\mathrm{Nunc}^{\mathrm{c}}$, preenchidas por mistura gasosa de $5 \% \mathrm{CO}_{2}, 5 \% \mathrm{O}_{2}$ e $90 \% \mathrm{~N}_{2}$, em estufa a $39^{\circ} \mathrm{C}$ (PALMA et al., 1998).

Foram avaliadas as taxas de clivagem, no dia 2 (D2), as taxas de blastocistos no dia 7 (D7) e blastocistos expandidos e eclodidos no dia 9 (D9) de cultivo, além da taxa de eclosão, no D9. O dia da inseminação foi considerado como o dia Zero (D0). Após a avaliação da taxa de desenvolvimento no D9, os blastocistos eclodidos dos grupos controle, T6 e T12 foram fixados em paraformolaldeído a $2 \%$, para a realização da contagem do número de células. Os embriões foram corados com Hoechst na concentração final de $10 \mu \mathrm{g} / \mathrm{mL}$ de PBS salino. A visualização foi efetuada em microscópio de epifluorescência equipado com filtro de excitação (365mm) e filtro de barreira (410 $\mathrm{nm})$.

Foram efetuadas 11 repetições e os dados foram analisados pelo Procedimento GLM, do pacote estatístico SAS (Release 6.12-1998), sendo as médias comparadas pelo teste de Tukey com nível de significância de $5 \%$.

\section{RESULTADOS}

$\mathrm{Na}$ avaliação efetuada em D2, as taxas de clivagem dos grupos submetidos ao transportesimulado durante 6,12 e 18 h não diferiram $(\mathrm{P}>0,05)$ das observadas no grupo Controle (Tabela 1), demonstrando não existir efeito prejudicial do transporte simulado sobre essa resposta.

Ao comparar o desenvolvimento embrionário em D7 (Tabela 1), as taxas foram semelhantes $(\mathrm{P}>0,05)$ para os grupos Controle, T6 e $\mathrm{T} 12$, observando-se, porém, redução significativa $(\mathrm{P}<0,05)$ no Grupo T18, em relação ao grupo Controle 
Tabela 1 - Desenvolvimento in vitro de embriões bovinos com oócitos mantidos em meio de maturação TCM+HEPES sem controle de atmosfera gasosa por diferentes períodos de transporte simulado.

\begin{tabular}{lccccc}
\hline Tratamentos & Oócitos & \% Clivagem & $\%$ Blastocistos & \% Eclosão \\
& $\mathrm{n}$ & Dia 2 & Dia 7 & Dia 9 & Dia 9* \\
\hline Controle & 296 & $84,1^{\mathrm{a}}$ & $20,9^{\mathrm{a}}$ & $19,6^{\mathrm{a}}$ & $37,9^{\mathrm{a}}$ \\
Transporte 6h (T6) & 286 & $81,5^{\mathrm{a}}$ & $19,2^{\mathrm{ab}}$ & $17,5^{\mathrm{a}}$ & $48,0^{\mathrm{a}}$ \\
Transporte 12h (T12) & 294 & $85,4^{\mathrm{a}}$ & $21,4^{\mathrm{a}}$ & $18,4^{\mathrm{a}}$ & $46,3^{\mathrm{a}}$ \\
Transporte 18h (T18) & 301 & $76,1^{\mathrm{a}}$ & $12,3^{\mathrm{b}}$ & $8,6^{\mathrm{b}}$ & $38,5^{\mathrm{a}}$ \\
\hline
\end{tabular}

${ }^{\mathrm{ab}}$ letras diferentes, na mesma coluna indicam diferença significativa $(\mathrm{P}<0,05)$

* Calculados sobre o número de blastocistos em D9

e T12. Em D9, observou-se menor $(\mathrm{P}<0,05)$ produção de blastocistos (expandidos mais eclodidos) no grupo T18 em relação aos grupos T6, T12 e Controle, embora não tenha sido observada diferença $(\mathrm{P}>0,05)$ na taxa de eclosão.

O número de células dos blastocistos eclodidos do grupo Controle não diferiu $(\mathrm{P}>0,05)$ do grupo T6 e T12 (Tabela 2). Os embriões do grupo T18 não foram submetidos à contagem de células, por terem apresentado índices de desenvolvimento inferiores aos demais grupos, o que inviabiliza sua utilização como prática de transporte.

\section{DISCUSSÃO}

O meio utilizado para o transporte é um dos principais fatores que interferem no desenvolvimento embrionário na PIV (GARCIA et al., 1998). Entretanto, poucos trabalhos têm sido conduzidos para avaliar os diversos fatores que podem influenciar este transporte. A utilização de meios de maturação com a adição de hormônios no transporte de oócitos, objeto do presente estudo, é importante para o posterior desenvolvimento embrionário, pois proporciona aos oócitos condições adequadas de maturação, já durante o transporte. GARCIA et al. (1998) obtiveram resultados superiores de PIV com o transporte de oócitos em meio de maturação, quando comparado a meios de manutenção. Substâncias como o Fluído Folicular bovino (FFb) têm sido utilizadas no transporte de oócitos bovinos (MONTAGNER et al., 1997; LEHMKUHL et al., 2000; VIZCARRA et al., 2000), com resultados satisfatórios, quando o período de transporte é relativamente curto. O FFb proporciona graus variáveis de bloqueio da meiose, possibilitando maior sincronia entre maturação nuclear e citoplasmática (LEHMKUHL, 2001), o que é adequado para a manutenção durante períodos curtos. Entretanto, para períodos mais prolongados de transporte, o bloqueio produzido pelo $\mathrm{FFb}$ pode determinar redução no posterior desenvolvimento embrionário, embora SCHWARTZ et al. (1998) tenham obtido bons resultados com a manutenção dos oócitos por $10 \mathrm{~h} \mathrm{a} 20^{\circ} \mathrm{C} \mathrm{em} \mathrm{FFb.} \mathrm{É} \mathrm{importante}$ ainda considerar o risco da introdução e transmissão de agentes infecciosos que possam estar presentes neste fluído (STRINGFELLOW et al., 2000), além da grande variação nos resultados de PIV, conforme a partida do FFb (LEHMKUHL, 2001). Esses inconvenientes são minimizados com a utilização do TCM+HEPES para o transporte dos oócitos destinados à PIV, o que proporciona resultados mais homogêneos e com menores riscos sanitários.

O HEPES vem sendo utilizado amplamente como tamponante em meios de transporte de oócitos, nas rotinas de OPU-PIV, sendo o meio TALP-HEPES (SCHERTHANER et al., 1998; WOLF et al., 1998) e o TCM-HEPES (SCHWARTZ et al., 1998; GARCIA et al., 1998; FRY et al., 2000) os mais empregados para este tipo de procedimento. SCHWARTZ et al. (1998) verificaram melhores resultados na PIV após a manutenção de oócitos bovinos em TCM-HEPES ou FFb, anteriormente à MIV, quando comparados ao TALP-HEPES.

Uma alternativa para períodos mais longos de transporte é a utilização de meios previamente equilibrados em estufa (TWAGIRAMUNGU et al., 1998; OLIVIER et al., 1998; WARD et al., 2000), que, todavia, apresentam resultados contraditórios, além do inconveniente da necessidade de prévia gaseificação e remessa para o local da OPU, o que dificulta muito sua aplicabilidade.

Tabela 2 - Número médio de células, visualizadas por coloração fluorescente com Hoechst, dos blastocistos bovinos eclodidos obtidos após a fecundação de oócitos submetidos ao transporte-simulado em meio de maturação TCM+HEPES por diferentes períodos

\begin{tabular}{lc}
\hline Tratamento & $\begin{array}{c}\text { Número de células } \pm \text { desvio- } \\
\text { padrão (variação) }\end{array}$ \\
\hline Controle $(\mathrm{n}=12)$ & $136,0 \pm 38,5$ \\
& $(78-210)$ \\
Transporte 6 horas $(\mathrm{n}=11)$ & $125,5 \pm 41,4$ \\
& $(82-203)$ \\
Transporte 12 horas $(\mathrm{n}=5)$ & $126,8 \pm 47,7$ \\
& $(65-197)$ \\
\hline
\end{tabular}

$\mathrm{P}>0,05$ 
No presente estudo, o número e a qualidade dos blastocistos não foram influenciados pelo tempo de transporte simulado, até $12 \mathrm{~h}$, em meio de maturação TCM+HEPES sem controle da atmosfera gasosa, corroborando os resultados de autores que utilizaram o HEPES como tampão no meio de manutenção e no transporte de oócitos durante curtos períodos, antes da MIV (SCHWARTZ et al., 1998; SCHERTHANER et al., 1998; TWAGIRAMUNGU et al., 1998; WARD et al., 2000) ou como meio de MIV no transporte em diferentes períodos e diferentes sistemas (GARCIA et al., 1998; FRY et al., 2000).

Poucos experimentos têm sido conduzidos para avaliar a influência da temperatura nas diferentes etapas da PIV, sendo normalmente utilizada a temperatura corporal da espécie. Sabe-se que variações bruscas de temperatura durante a coleta, transporte e cultivo de oócitos e embriões devem ser evitadas, para a máxima produção embrionária (BOONE \& SHAPIRO, 1990). SCHWARTZ et al. (1998) obtiveram melhores resultados de PIV mantendo oócitos bovinos antes da MIV em TCM-HEPES ou Fluído folicular bovino $(\mathrm{FFb})$ a $20^{\circ} \mathrm{C}$, do que a $39^{\circ} \mathrm{C}$. A temperatura utilizada no transporte-simulado, neste experimento é próxima à temperatura fisiológica da espécie, possibilitando a obtenção de resultados satisfatórios, que estão em acordo com os verificados por outros autores (NIBART et al., 1997; PEIXER et al., 1997; FRY et al., 2000; WARD et al., 2000).

O transporte durante $18 \mathrm{~h}$, apesar de não ter afetado a taxa de clivagem e a eclosão dos embriões que chegaram ao estágio de blastocisto, resultou em diminuição no número de blastocistos produzidos. Apesar de muitos trabalhos comprovarem a eficiencia do Hepes como tamponante do pH (TWAGIRAMUNGU et al. 1998; FRY et al., 2000; MONTAGNER et al., 2000), observou-se uma redução da viabilidade no grupo T18 que pode ter ocorrido pela incapacidade do tampão HEPES em manter o $\mathrm{pH}$ durante $18 \mathrm{~h}$, que pode ter determinado prejuízos no desenvolvimento posterior dos embriões. Entretanto, esta análise não foi realizada no presente estudo, sendo necessárias novas investigações que avaliem diferentes sistemas para o transporte, a troca ou reposição do meio após o período de $12 \mathrm{~h}$.

A metodologia empregada no presente trabalho, sem a necessidade de prévia gaseificação, oferece alternativa prática e eficiente para o transporte dos oócitos bovinos destinados à PIV, por até $12 \mathrm{~h}$, o que possibilita sua remessa a grandes distâncias, representando um método fácil, prático e aplicável na maioria dos laboratórios de PIV do País.

\section{CONCLUSÕES}

O transporte de oócitos bovinos, em meio de maturação TCM+HEPES, a $39^{\circ} \mathrm{C}$ sem controle de atmosfera gasosa por até $12 \mathrm{~h}$, não determina decréscimo nas taxas de desenvolvimento embrionário in vitro bem como no número de células dos blastocistos eclodidos. Esta técnica constitui-se numa alternativa prática e eficiente para a remessa até o laboratório de PIV, dos oócitos bovinos aspirados a campo.

\section{AGRADECIMENTOS}

A todos do Embryolab, pela colaboração para o bom andamento da pesquisa. À UFSM, pela estrutura cedida. Ao frigorífico JG de Caçapava do Sul, pela cedência dos ovários; à ABS Pecplan, pelo processamento do sêmen. A todos que participaram direta ou indiretamente deste projeto.

\section{FONTES DE AQUISIÇÃO}

a- Todas as fontes de aquisição, exceto as mencionadas abaixo são de Sigma Chemical Co. P4687 PO BOX 4508, MO., U.S.A. b- Nevoni Equipamento Odonto Médico Hospitalar Ltda - Rua Dom João V, 266/280 Lapa 05.075.060 São Paulo, SP, Brasil. c- Brand GmBh Co. Postfach 1155. D-97861 Wertheim, Alemanha

d- Cultilab Materiais para Cultura de Células Ltda. R. Maria Monteiro, 742, Campinas-SP

e- Serono Pharma S.p.A. 70.123, Bari, Itália.

f- Processado no Laboratório

g- Corning glass works, Corning, NY, 14831, U.S.A.

\section{REFERÊNCIAS BIBLIOGRÁFICAS}

BOONE, W.R.; SHAPIRO, S.S. Quality control in the in vitro fertilization laboratory. Theriogenology, v.33, p.23-50, 1990.

BRUM, D.S. et al. Transporte-cultivo de embriões bovinos produzidos in vitro. Arquivos da Faculdade de Veterinária da UFRGS, v.28, n.2, p.36-50, 2000.

BRUM, D.S. et al. Cultivo individual de blastocistos bovinos produzidos in vitro. Brazilian Journal of Veterinary Research and Animal Science, v.39, n.2, p.87-92, 2001.

De LOSS, F. et al. Morphology of immature bovine oocytes. Gamete Research, v.24, p.197-204, 1989.

FRY, R.C. et al. No difference in embryo production from oocytes collected by ovum pick-up from commercial cows when using either hepes- or bicarbonate-buffered IVM media. Theriogenology, v.53, n.1, p.304, 2000.

GARCIA, J. M., et al. Produção in vitro de embriões bovinos: diferentes procedimentos. Arquivos da Faculdade de Veterinária da UFRGS, v.26, p. 280, 1998, Suplemento.

LEHMKUHL, R.C. et al. Desenvolvimento embrionário de oócitos bovinos mantidos em líquido folicular e submetidos a FIV. Arquivos da Faculdade de Veterinária da UFRGS, v.28, p.276, 2000, Suplemento. 
LEHMKUHL, R.C. Desenvolvimento de oócitos bovinos mantidos em líquido folicular. 2001. 21f. Dissertação (Mestrado em Fisiopatologia da Reprodução) - Programa de Pós-graduação em Medicina Veterinária, Universidade Federal de Santa Maria.

LEIVAS F.G. et al. Desenvolvimento embrionário in vitro de oócitos bovinos mantidos em meio de maturação não gaseificado. Revista Brasileira de Reprodução Animal, v. 25 n.1 p.414-415, 2001.

MEZZALIRA, A. et al. Transporte de embriões bovinos fecundados in vitro. Arquivos da Faculdade de Veterinária da UFRGS, v.26, p.312, 1998, Suplemento

MONTAGNER, M.M. et al. Desenvolvimento embrionário após a permanência de oócitos bovinos em líquido folicular in vitro. Arquivos da Faculdade de Veterinária da UFRGS, v.25, p.252, 1997, Suplemento.

MONTAGNER, M.M. et al. HEPES na produção de embriões bovinos in vitro. Ciência Rural, v.30, n.3, p.469-474, 2000 .

NIBART, M. et al. The Application of new reproductive technologies in France. Arquivos da Faculdade de Veterinária da UFRGS, v.25, p.21-35, 1997, Suplemento.

OLIVIER, N. et al. The use of polystyrol tubes and waterbath for in vitro production of bovine embryos. In: REUNION A.E.T.E., 14e., 1998, Venise. Proceedings... Venise : AETE, 1998. p. 220 .

PALMA, G.A. et al. In vitro development and viability of bovine embryos produced without gassed incubator. Theriogenology, v. 49, p.213, 1998.

PEIXER M.A.S. et al. Obtenção de gestações pelo sistema MIV-t em vacas de sub-fertilidade adquirida. Arquivos da Faculdade de Veterinária da UFRGS, v.25, p.276, 1997, Suplemento.
ROSE, T.A.; BAVISTER B.D. Effect of oocyte maturation medium on in vitro developmental of in vitro fertilized bovine embryos. Molecular Reproduction and Development, v.31, p.72-77, 1992.

SCHNEIDER, M.R. et al. Short-term storage of in vitro produced bovine embryos. Theriogenology, v.49, n.1, p.249, 1998.

SCHERTHANER, W. et al. Storage of bovine oocytes after ultrasound guided follicle aspiration: Effects on developmental competence. In: REUNION A.E.T.E., 14e., 1998, Venise. Proceedings... Venise : A.E.T.E., 1998. p.242.

SCHWARTZ, J. et al. Effect of short-term storage of bovine oocytes in different media and temperatures on the subsequent in vitro embryo development. Theriogenology, v.49, n.1, p.217, 1998.

STRINGFELLOW, D.A. et al. Quality controls for bovine viral diarrhea virus-free IVF embryos. Theriogenology, v.53, p.827-839, 2000.

TWAGIRAMUNGU, H. et al. Media and time of oocytes transport influence their developmental competence for in vitro production of bovine embryos. Theriogenology, v.49, n.1, p.299, 1998.

VIZCARRA, V.E.L. et al. Efeito do fluído folicular na manutenção de oócitos recém aspirados de bovinos. Arquivos da Faculdade de Veterinária da UFRGS, v.28, p.343, 2000, Suplemento.

WARD, F. A. et al. Factors affecting recovery and quality of oocytes for bovine embryo production in vitro using ovum pick-up technology. Theriogenology, v.54, p.433-446, 2000.

WOLF, E. et al. Recent progress in the in vitro production and cloning of bovine embryos. Arquivos da Faculdade de Veterinária da UFRGS, v.26, p.161-178, 1998, Suplemento. 